\title{
B. anthracis associated cardiovascular dysfunction and shock: the potential contribution of both non-toxin and toxin components
}

\author{
Kenneth E Remy, Ping Qiu, Yan Li, Xizhong Cui and Peter Q Eichacker*
}

\begin{abstract}
The development of cardiovascular dysfunction and shock in patients with invasive Bacillus anthracis infection has a particularly poor prognosis. Growing evidence indicates that several bacterial components likely play important pathogenic roles in this injury. As with other pathogenic Gram-positive bacteria, the B. anthracis cell wall and its peptidoglycan constituent produce a robust inflammatory response with its attendant tissue injury, disseminated intravascular coagulation and shock. However, B. anthracis also produces lethal and edema toxins that both contribute to shock. Growing evidence suggests that lethal toxin, a metalloprotease, can interfere with endothelial barrier function as well as produce myocardial dysfunction. Edema toxin has potent adenyl cyclase activity and may alter endothelial function, as well as produce direct arterial and venous relaxation. Furthermore, both toxins can weaken host defense and promote infection. Finally, B. anthracis produces non-toxin metalloproteases which new studies show can contribute to tissue injury, coagulopathy and shock. In the future, an understanding of the individual pathogenic effects of these different components and their interactions will be important for improving the management of $B$. anthracis infection and shock.
\end{abstract}

Keywords: Bacillus anthracis, Anthrax, Cell wall components, Lethal and edema toxins, Metalloproteases, Cardiovascular dysfunction, Shock

\section{Introduction}

Recent outbreaks of Bacillus anthracis infection in the United States (US) and Europe have underscored the importance of this bacterium in the developed world [1-4]. Despite aggressive support, mortality rates in these outbreaks have been high; $40 \%$ in the 2001 US outbreak of inhalational infection, and 33\% in the 2009 outbreak of injectional disease in Scotland $[2,4,5]$. During these outbreaks, the development of shock in patients has appeared resistant to standard hemodynamic therapy and has been associated with a particularly poor prognosis [1-3]. Therefore, an increased understanding of the mechanisms producing shock during $B$. anthracis infection will be important for its management.

Evolving research has shown that $B$. anthracis produces several components potentially important in the pathogenesis of shock, including its two exotoxins (lethal and

* Correspondence: peichacker@mail.cc.nih.gov

Critical Care Medicine Department, Clinical Center, National Institutes of Health, Bethesda, MD 20892, USA edema toxins (LT and ET, respectively)), a cell wall and its constituents, and several non-toxin metalloproteases. Notably, although LT and ET have long been a focus in this area of research, newer data have begun to emphasize the role of these non-toxin components. This review highlights recent research directed at the contribution of these different non-toxin and toxin components.

\section{B. anthracis cell wall and its peptidoglycan constituent} Sepsis is thought to typically start as a nidus of infection, followed by bacterial invasion of the blood stream. Bacterial cell wall and other components interact with pathogen recognition receptors (PRRs) on host cells; host defense systems are activated; and inflammatory mediators (for example, cytokines, nitric oxide and oxygen free radicals) are released [6]. While this inflammatory response is an essential part of innate immunity and is necessary for microbial clearance, an excessive response can produce organ injury and shock [7-9]. Growing evidence suggests

\section{() Biomed Central}


that $B$. anthracis infection can elicit this type of maladaptive injurious host inflammatory response (Figure 1A) $[10,11]$.

While lethal and edema toxins are now recognized not to stimulate excessive inflammation (and may actually suppress it), the vegetative form of $B$. anthracis has a cell wall comprised largely of peptidoglycan that can promote such inflammation [12-14]. Whole cell wall and/or purified peptidoglycan can interact with toll-like receptors two and six (TLR2/6) and nucleotide-binding oligomerization domains 1 and 2 (NOD1 and 2) proteins $[15,16]$. They can also stimulate host release of TNFo, IL-1 $\beta$ IL- 6 and other inflammatory mediators [17]. In rats, in contrast to LT or ET, purified B. anthracis cell wall or its peptidoglycan component alone can stimulate a robust inflammatory response with resultant tissue injury, shock, disseminated intravascular coagulation and lethality $[18,19]$. Relevant to these findings, $B$. anthracis peptidoglycan can activate platelets through complement activation [20]. The potential pathogenic role of cell wall takes on added importance based on the observation that patients and animals dying from $B$. anthracis frequently have very high bacterial loads $[2,13,19]$. Therefore, while much attention has been devoted to the unique roles LT and ET have in the pathogenesis of B. anthracis, this

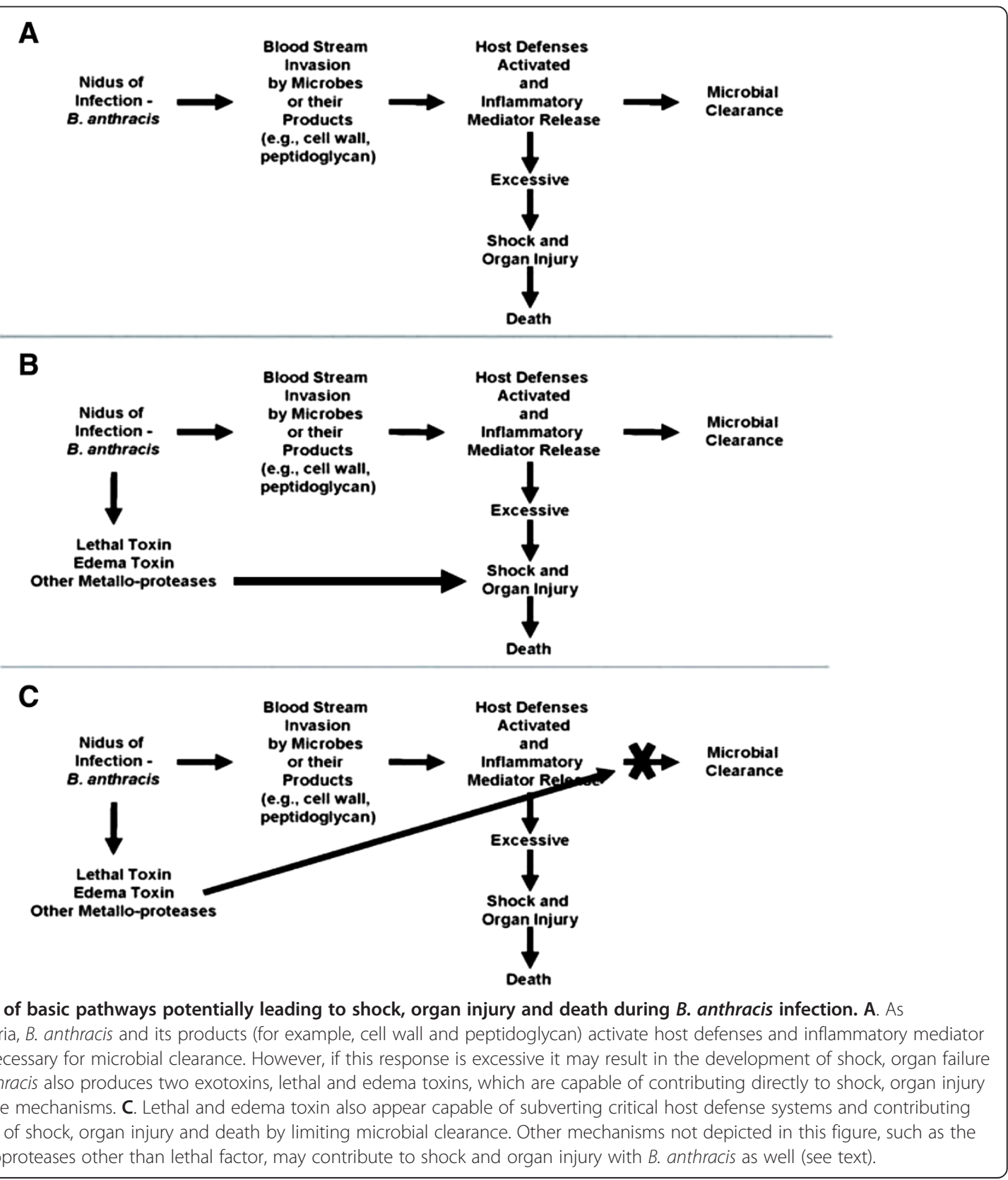


Gram-positive bacteria can also produce shock and organ injury via mechanisms common to other types of bacteria.

Lethal and edema toxin structure and intracellular effects Lethal and edema toxins are each binary type exotoxins comprised of protective antigen (PA) and the toxic moieties lethal factor (LF) and edema factor (EF) [14,21,22]. During infection, PA binds to host cells via one of two receptors: tumor endothelial marker 8 (TEM8) or capillary morphogenesis gene-2 (CMG2) [23-25]. These receptors are abundant on endothelial cells and in a variety of tissues [14]. PA binding is necessary for host cell uptake of LF and EF. LF inactivates mitogen-activated protein kinase kinases 1 to 4, 6 and 7 (MAPKKs) [21,22]. Recent data also show that LF activates the Nlrp1 inflammasome in macrophages and dendritic cells causing activation of caspase- 1 and the production of IL-1 $\beta$ and IL-18 and, subsequently cell death [26-28]. EF has potent calmodulin-dependent adenyl cyclase activity and increases intracellular concentrations of cyclic adenosine monophosphate (cAMP) and possibly other cyclic nucleotides [29,30]. While neither toxin stimulates a robust inflammatory response, growing evidence demonstrates that each can contribute to cardiovascular dysfunction and shock (Figure 1B).

\section{Lethal toxin}

Studies in an instrumented canine model clearly demonstrated that LT produces profound cardiovascular dysfunction. Twenty-four-hour LT infusions to simulate toxin release during infection resulted in reductions in central venous pressure (CVP) and mean arterial blood pressure (MAP) that persisted for up to 72 hours $[31,32]$. These changes occurred in patterns similar to those in patients with $B$. anthracis infection and shock; and were greater in non-survivors than survivors. Hemodynamic effects such as these frequently reflect peripheral vascular dysfunction related either to endothelial barrier dysfunction with extravasation of fluid or direct dilation of arterial resistance or venous capacitance vessels. Consistent with such effects, administration of fluids and vasopressors in this LT-challenged model increased CVP, MAP and survival [32]. Inhibition of LT with a PA-directed monoclonal antibody (mAb) further increased these parameters. A growing number of in vitro studies provide a basis for

Table 1 Selected in vitro studies implicating lethal (LT) or edema toxin (ET) in endothelial cell dysfunction

\begin{tabular}{|c|c|c|c|}
\hline Study & Toxin & Cell type & Toxin effect \\
\hline Rolando, M. 2010 & $\mathrm{LT}$ & HUVEC & $\begin{array}{l}\text { Exerted cytotoxic effects on endothelial cell monolayers with } \\
\text { elongation and redistribution of VE-cadherin and subsequent } \\
\text { cell death; increased caspase-3, } 8 \text { and } 9 \text { activity. Up-regulation } \\
\text { of TNF-related apoptosis-inducing ligand (TRAIL) and } \\
\text { down-regulation of xaf1 (XIAP associated factor-1) participated } \\
\text { in LT-induced caspase-3 activation; increased caspase-3 } \\
\text { dependent cortactin and rhophilin-2 activity in combination } \\
\text { with calponin-1 expression appeared necessary for LT } \\
\text { mediated actin cable formation. }\end{array}$ \\
\hline
\end{tabular}

Guichard, A. 2010

LT

Warfel, J. 2011

LT

Liu, T. 2012

Guichard, A. 2010

$E T$

Maddugoda, M. 2011

ET

Ebrahimi, C. 2011
Human brain, dermal and lung microvascular endothelial cells (HBMEC, HDMEC and HMVEC-LS, respectively)

Human lung microvascular endothelial cells
ET

Rat pulmonary microvascular endothelial cells

Human brain, dermal and lung microvascular endothelial cells (HBMEC, HDMEC and HMVEC-LS, respectively)

Mouse endothelial cells, HUVEC

HBMEC
Lethal factor (LF) worked synergistically with edema factor (EF) to reduce DE-cadherin levels at adherens junctions in HBMEC, HDMECS and HMVEC-LS.

Increased monolayer permeability, effects on permeability associated with the activation of Rho associated kinase (ROCK-1) and increased myosin light chain (MLC) phosphorylation and subsequent actin stress fiber formation and VE-cadherin gene and protein expression inhibition.

Increased gap formation and permeability of endothelial cell monolayers; decreased p38 signaling; permeability effects overcome by PmHSP27 over-expression.

Edema factor (EF) worked synergistically with lethal factor (LF) to reduce DE-cadherin levels at adherens junctions in HBMEC, HDMECS and HMVEC-LS.

EF increased the permeability of HBMEC trans-well monolayers.

Stimulated trans-endothelial macro-aperture (TEM) tunnel formation and increased endothelial permeability potentially via CAMP mediated mechanisms.

Disrupted tight junction formation and barrier function and monolayer integrity; contributed to disruption of endothelial cells and ZO-1, a primary regulatory protein of tight junction formation in the blood-brain barrier. 
these changes with LT. Table 1 briefly summarizes findings from recent studies demonstrating that LT may interfere with endothelial barrier function via several mechanisms including: disruption of endothelial cell stress kinase pathways, endothelial apoptosis, and alterations in actin fiber and cadherin function [33-36]. However, in contrast to its potential deleterious effects on endothelial barrier function, LT did not produce direct arterial dilation in an isolated aortic ring model [37].

Evidence also suggests that LT depresses myocardial function. In canines, a 24-hour LT infusion caused progressive decreases in left ventricular ejection fraction (LVEF) that were blocked by PA-mAb $[31,32]$. Although CVP was reduced, pulmonary artery occlusion pressure was not, suggesting that decreased preload was not the primary basis for LVEF reductions. Similar to mice, more recent work in rabbits demonstrated that LT produced direct myocardial injury with dose dependent cardiac necrosis and increases in cardiac biomarkers [38,39]. In in vitro studies, LT altered intracellular cardiomyocyte-Ca ${ }^{++}$handling and depressed cardiomyocyte function [40]. LT associated dysregulation of autophagy, ubiquitin-proteasome, and mitochondrial function may have contributed to this cardiomyocyte depression via TLR-4 [41,42]. Thus, hypotension in patients with B. anthracis may also relate to the inhibitory effects of LT on cardiac function. However, in contrast to data supporting a myocardial depressant effect of LT in studies in an isolated perfused rat heart model, LT only altered myocardial function when administered in doses substantially higher than those producing lethality in vivo [43]. Furthermore, observations in patients with $B$. anthracis infection, while limited, have not demonstrated consistent abnormalities in myocardial function [1-3].

In addition to its direct cardiovascular effects, LT may contribute to shock by promoting $B$. anthracis infection [44]. LT inactivates MAPKK pathways central to innate and adaptive immune responses and, therefore, may impair host defense and microbial clearance [22,25,45-47]. In one murine model, pretreatment with sublethal LT doses before intravenous $E$. coli challenge, increased blood bacterial counts and worsened survival [48]. Moreover, pretreatment of rats with sub-lethal LT doses inhibited inflammatory mediator release stimulated by lipopolysaccharide (LPS) or E. coli challenges [14]. These inhibitory effects of LT on immune responses have been proposed as a basis for the high bacterial loads noted in patients dying with $B$. anthracis infection $[13,19,21,22]$.

\section{Edema toxin}

Increasing evidence indicates that ET may also be important in the pathogenesis of shock during B. anthracis infection. Twenty-four-hour ET challenge in canines produced rapid and profound reductions in CVP, MAP and systemic vascular resistance (SVR) that persisted for 72 hours [31].
Recent in vitro studies, summarized in Table 1, suggest that ET may impair endothelial barrier function by altering adherens' junction function or by inducing transendothelial macro-aperture tunnels $[36,49,50]$. However, endothelial impairment is not entirely consistent with EFs' recognized action as a potent adenyl-cyclase, since increased cellular cAMP levels may actually have protective effects on endothelial barrier function $[12,51,52]$. Consistent with this, ET in one study increased endothelial barrier resistance [53]. Alternatively, very high cAMP levels and their intracellular location may have paradoxical effects on endothelial integrity resulting in a net loss of barrier function [12,51,52].

Growing data suggests that EFs' potent adenyl cyclase actions may stimulate direct arterial or venous dilation. It is well known that increased intracellular cAMP levels stimulate vascular smooth muscle relaxation [54,55]. The very rapid reductions in CVP, MAP and SVR noted with ET in the canine model were consistent with a direct vasorelaxant effect rather than with disruption of endothelial barrier function and extravasation of fluid [31]. Findings from two ex vivo models further support this possibility. In an isolated perfused rat heart model, ET produced significant increases in coronary flow rate (CFR) consistent with a direct vasodilatory effect [43]. These changes with ET were associated with increases in both myocardial tissue and effluent cAMP levels. Adefovir, a nucleoside which interferes with EF adenyl-cyclase activity, inhibited these ET effects [56,57]. In a rat aortic ring model, incubation with ET increased cAMP levels and reduced arterial responsiveness to subsequent contraction with phenylephrine [37]. ET also caused relaxation in rings already pre-contracted with phenylephrine. This ability of ET to inhibit catecholamine function may provide a basis for the resistance to conventional hemodynamic support noted in patients with injectional B. anthracis infection [1-3].

Finally, ET may augment the effects of LT. In mouse, rat and canine models, nonlethal ET doses increased the lethality of LT $[14,31]$. ET also potentiated the inhibitory effects of LT on chemotaxis and the function of dendritic and T-cells [14]. ET's ability to up-regulate the expression of PA receptors on macrophages and dendritic cells in vitro and to increase the rate of toxin internalization may provide a basis for synergism with LT [58]. Growing recognition of ET's potential role in the pathogenesis of shock with $B$. anthracis suggests that if toxin-directed therapies are to be considered for patients, they should be directed at both LT and ET [2].

\section{Non-toxin metalloproteases}

Besides LF, $B$. anthracis produces other metalloproteases potentially important in the pathogenesis of vascular and nonvascular tissue injury. The delta Ames (pXO1 ${ }^{-}$and $\mathrm{pXO}{ }^{-}$) B. anthracis strain produces metalloproteases 
belonging to the M4 thermolysin and M9 bacterial collagenase families $[59,60]$. In murine models, administration of these metalloproteases produced hemorrhagic tissue injury while treatment with selective metalloprotease-inhibitors improved survival $[61,62]$. B. anthracis metalloproteases Npr599 and InhA cleaved host structural and regulatory proteins important in endothelial function, including plasma ADAMTS13, von Willebrand factor (VWF) substrate FRETS-VWF73, and VWF itself [63]. InhA also stimulated plasminogen activator inhibitor (PAI-1) in mouse liver and increased blood-brain barrier permeability in both mouse brain and human brain microvasculature endothelial cells by disrupting endothelial tight junction proteins $[61,62,64,65]$. What the relative roles are of LF and these other metalloproteases during shock in patients with $B$. anthracis infections require study.

\section{Conclusions}

There is growing evidence that the pathogenesis of cardiovascular dysfunction and shock during $B$. anthracis infection is complex and likely involves both non-toxin and toxin components. Further understanding of how these components interact is essential for improving the management of severe B. anthracis infection and shock.

\section{Abbreviations \\ CAMP: Cyclic adenosine monophosphate; CFR: Coronary flow rate; CMG-2: Capillary morphogenesis gene-2; CVP: Central venous pressure; EF: Edema factor; ET: Edema toxin; HBMEC: Human brain microvascular endothelial cells; HDMEC: Human dermal microvascular endothelial cells; HMVEC-L: Human lung microvascular endothelial cells; HUVEC: Human umbilical vein endothelial cells; IL: Interleukin; LF: Lethal factor; LPS: Lipopolysaccharide; LT: Lethal toxin; LVEF: Left ventricular ejection fraction; MAPKinase: Mitogen activated protein kinase; MLC: Myosin light chain; NLRP: Nod Like Receptor Protein; NOD: Nucleotide-binding oligomerization domains; PA: Protective antigen; PAI-1: Plasminogen activator inhibitor; PRRs: Pathogen recognition receptors; ROCK-1: Rho associated kinase; SVR: Systemic vascular resistance; TEM: Trans-endothelial cell macro-aperture; TEM-8: Tumor endothelial marker-8; TLR: Toll like receptor; TNF: Tumor necrosis factor; TRAIL: TNF-related apoptosis- inducing ligand.}

\section{Competing interests}

None of the authors have competing interests to report.

\section{Authors' contributions}

All authors (KER, PQ, YL, XC and PQE) have contributed to the formulation, writing and editing of this review. All authors read and approved the final manuscript.

\section{Acknowledgements}

This research was supported by the Intramural Program of the $\mathrm{NIH}$, Clinical Center, Critical Care Medicine Department.

Received: 11 December 2012 Accepted: 13 September 2013 Published: 9 October 2013

\section{References}

1. Booth MG, Hood J, Brooks TJ, Hart A: Anthrax infection in drug users. Lancet 2010, 375:1345-1346.

2. Hicks CW, Sweeney DA, Cui X, Li Y, Eichacker PQ: An overview of anthrax infection including the recently identified form of disease in injection drug users. Intensive Care Med 2012, 38:1092-1104.

3. Booth M, Donaldson L, Xizhong C, Junfeng S, Eichacker P: Comparison of survivors and nonsurvivors in 27 confirmed injectional anthrax cases from the 2009 outbreak in scotland. Crit Care 2013, 17:668.
4. National Anthrax Outbreak Control Team: An Outbreak of Anthrax among Drug Users in Scotland, December 2009 to December 2010. Glasgow: Health Protection Scotland; 2011.

5. Jernigan JA, Stephens DS, Ashford DA, Omenaca C, Topiel MS, Galbraith M, Tapper M, Fisk TL, Zaki S, Popovic T, Meyer RF, Quinn CP, Harper SA, Fridkin SK, Sejvar JJ, Shepard CW, McConnell M, Guarner J, Shieh WJ, Malecki JM, Gerberding $J$, Hughes JM, Perkins BA: Bioterrorism-related inhalational anthrax: the first 10 cases reported in the United States. Emerg Infect Dis 2001, 7:933-944.

6. Seeley EJ, Matthay MA, Wolters PJ: Inflection points in sepsis biology: from local defense to systemic organ injury. Am J Physiol Lung Cell Mol Physiol 2012, 303:L355-363

7. Cinel I, Opal SM: Molecular biology of inflammation and sepsis: a primer. Crit Care Med 2009, 37:291-304.

8. Suffredini AF, Munford RS: Novel therapies for septic shock over the past 4 decades. JAMA 2011, 306:194-199.

9. Aziz M, Jacob A, Yang WL, Matsuda A, Wang P: Current trends in inflammatory and immunomodulatory mediators in sepsis. J Leukocyte Biol 2013, 93:329-342.

10. Pickering AK, Merkel TJ: Macrophages release tumor necrosis factor alpha and interleukin-12 in response to intracellular Bacillus anthracis spores. Infect Immun 2004, 72:3069-3072.

11. Stearns-Kurosawa DJ, Lupu F, Taylor FB Jr, Kinasewitz G, Kurosawa S: Sepsis and pathophysiology of anthrax in a nonhuman primate model. Am J Pathol 2006, 169:433-444.

12. Guichard A, Nizet $V$, Bier E: New insights into the biological effects of anthrax toxins: linking cellular to organismal responses. Microbes Infect 2012, 14:97-118.

13. Coggeshall KM, Lupu F, Ballard J, Metcalf JP, James JA, Farris D, Kurosawa S: The sepsis model: an emerging hypothesis for the lethality of inhalation anthrax. J Cell Mol Med 2013, 17:914-920.

14. Hicks CW, Cui X, Sweeney DA, Li Y, Barochia A, Eichacker PQ: The potential contributions of lethal and edema toxins to the pathogenesis of anthrax associated shock. Toxins 2011, 3:1185-1202.

15. Triantafilou M, Uddin A, Maher S, Charalambous N, Hamm TS, Alsumaiti A, Triantafilou K: Anthrax toxin evades toll-like receptor recognition, whereas its cell wall components trigger activation via t|r2/6 heterodimers. Cell Microbiol 2007, 9:2880-2892.

16. Langer M, Malykhin A, Maeda K, Chakrabarty K, Williamson KS, Feasley CL, West CM, Metcalf JP, Coggeshall KM: Bacillus anthracis peptidoglycan stimulates an inflammatory response in monocytes through the p38 mitogen-activated protein kinase pathway. PLoS One 2008, 3:e3706.

17. Iyer JK, Khurana T, Langer M, West CM, Ballard JD, Metcalf JP, Merkel TJ, Coggeshall KM: Inflammatory cytokine response to Bacillus anthracis peptidoglycan requires phagocytosis and lysosomal trafficking. Infect Immun 2010, 78:2418-2428.

18. Cui X, Su J, Li Y, Shiloach J, Solomon S, Kaufman JB, Mani H, Fitz Y, Weng J, Altaweel L, Besch V, Eichacker PQ: Bacillus anthracis cell wall produces injurious inflammation but paradoxically decreases the lethality of anthrax lethal toxin in a rat model. Intensive Care Med 2010, 36:148-156.

19. Qiu P, Li Y, Shiloach J, Cui X, Sun J, Trinh L, Kubler-Kielb J, Vinogradov E, Mani H, Al-Hamad M, Fitz Y, Eichacker PQ: B. anthracis cell wall peptidoglycan but not lethal or edema toxins produces changes consistent with disseminated intravascular coagulation in a rat model. J Infect Dis 2013, 208:978-989.

20. Sun D, Popescu NI, Raisley B, Keshari RS, Dale GL, Lupu F, Coggeshall KM: Bacillus anthracis peptidoglycan activates human platelets through FcyRII and complement. Blood 2013, 122:571-579.

21. Sweeney DA, Hicks CW, Cui X, Li Y, Eichacker PQ: Anthrax infection. Am J Resp Crit Care 2011, 184:1333-1341.

22. Lowe DE, Glomski IJ: Cellular and physiological effects of anthrax exotoxin and its relevance to disease. Front Cell Infect Microbiol 2012, 2:76.

23. Liu S, Miller-Randolph S, Crown D, Moayeri M, Sastalla I, Okugawa S, Leppla $\mathrm{SH}$ : Anthrax toxin targeting of myeloid cells through the CMG2 receptor is essential for establishment of Bacillus anthracis infections in mice. Cell Host Microbe 2010, 8:455-462.

24. Akkaladevi N, Hinton-Chollet L, Katayama H, Mitchell J, Szerszen L, Mukherjee S, Gogol EP, Pentelute BL, Collier RJ, Fisher MT: Assembly of anthrax toxin pore: lethal-factor complexes into lipid nanodiscs. Protein Sci 2013, 22:492-501

25. Liu S, Zhang Y, Hoover B, Leppla SH: The receptors that mediate the direct lethality of anthrax toxin. Toxins 2013, 5:1-8. 
26. Moayeri M, Leppla SH: Cellular and systemic effects of anthrax lethal toxin and edema toxin. Mol Aspects Med 2009, 30:439-455.

27. Chavarria-Smith J, Vance RE: Direct proteolytic cleavage of NLRP1B is necessary and sufficient for inflammasome activation by anthrax lethal factor. PLoS Pathog 2013, 9:e1003452.

28. Levinsohn JL, Newman ZL, Hellmich KA, Fattah R, Getz MA, Liu S, Sastalla I, Leppla SH, Moayeri M: Anthrax lethal factor cleavage of NLRP1 is required for activation of the inflammasome. PLoS Pathog 2012, 8:e1002638.

29. Laine $E$, Martinez $L$, Blondel A, Malliavin TE: Activation of the edema factor of Bacillus anthracis by calmodulin: evidence of an interplay between the EF-calmodulin interaction and calcium binding. Biophys J 2010, 99:2264-2272.

30. Gottle M, Dove S, Kees F, Schlossmann J, Geduhn J, Konig B, Shen Y, Tang WJ, Kaever V, Seifert R: Cytidylyl and uridylyl cyclase activity of Bacillus anthracis edema factor and Bordetella pertussis CyaA. Biochemistry 2010, 49:5494-5503.

31. Sweeney DA, Cui X, Solomon SB, Vitberg DA, Migone TS, Scher D, Danner RL, Natanson C, Subramanian GM, Eichacker PQ: Anthrax lethal and edema toxins produce different patterns of cardiovascular and renal dysfunction and synergistically decrease survival in canines. J Infect Dis 2010, 202:1885-1896.

32. Barochia AV, Cui X, Sun J, Li Y, Solomon SB, Migone TS, Subramanian GM, Bolmer SD, Eichacker PQ: Protective antigen antibody augments hemodynamic support in anthrax lethal toxin shock in canines. J Infect Dis 2012, 205:818-829.

33. Rolando M, Stefani C, Flatau G, Auberger P, Mettouchi A, Mhlanga M, Rapp U, Galmiche A, Lemichez E: Transcriptome dysregulation by anthrax lethal toxin plays a key role in induction of human endothelial cell cytotoxicity. Cell Microbiol 2010, 12:891-905.

34. Warfel JM, D'Agnillo F: Anthrax lethal toxin-mediated disruption of endothelial ve-cadherin is attenuated by inhibition of the rho-associated kinase pathway. Toxins 2011, 3:1278-1293.

35. Liu T, Milia E, Warburton RR, Hill NS, Gaestel M, Kayyali US: Anthrax lethal toxin disrupts the endothelial permeability barrier through blocking p38 signaling. J Cell Physiol 2012, 227:1438-1445

36. Guichard A, McGillivray SM, Cruz-Moreno B, van Sorge NM, Nizet V, Bier E: Anthrax toxins cooperatively inhibit endocytic recycling by the Rab11/Sec15 exocyst. Nature 2010, 467:854-858.

37. Li Y, Cui X, Solomon SB, Remy K, Fitz Y, Eichacker PQ: B. anthracis edema toxin increases camp levels and inhibits phenylephrine stimulated contraction in a rat aortic ring model. Am J Physiol Heart Circ Physiol 2013, 305: $\mathrm{H} 238-250$.

38. Lawrence WS, Marshall JR, Zavala DL, Weaver LE, Baze WB, Moen ST, Whorton EB, Gourley RL, Peterson JW: Hemodynamic effects of anthrax toxins in the rabbit model and the cardiac pathology induced by lethal toxin. Toxins 2011, 3:721-736.

39. Moayeri M, Crown D, Dorward DW, Gardner D, Ward JM, Li Y, Cui X, Eichacker $\mathrm{P}$, Leppla SH: The heart is an early target of anthrax lethal toxin in mice: A protective role for neuronal nitric oxide synthase (nNos). PLoS Pathog 2009, 5:e1000456.

40. Kandadi MR, Hua Y, Ma H, Li Q, Kuo SR, Frankel AE, Ren J: Anthrax lethal toxin suppresses murine cardiomyocyte contractile function and intracellular Ca2+ handling via a NADPH oxidase-dependent mechanism. PloS one 2010, 5:e13335.

41. Kandadi MR, Yu X, Frankel AE, Ren J: Cardiac-specific catalase overexpression rescues anthrax lethal toxin-induced cardiac contractile dysfunction: role of oxidative stress and autophagy. BMC Med 2012, 10:134.

42. Kandadi MR, Frankel $A E$, Ren J: Toll-like receptor 4 knockout protects against anthrax lethal toxin-induced cardiac contractile dysfunction: role of autophagy. Br J Pharmacol 2012, 167:612-626.

43. Hicks CW, Li Y, Okugawa S, Solomon SB, Moayeri M, Leppla SH, Mohanty A Subramanian GM, Mignone TS, Fitz Y, Cui X, Eichacker PQ: Anthrax edema toxin has CAMP-mediated stimulatory effects and high-dose lethal toxin has depressant effects in an isolated perfused rat heart model. Am J Physiol Heart Circ Physiol 2011, 300:H1108-1118.

44. Barua S, Iyer JK, Larabee JL, Raisley B, Hughes MA, Coggeshall KM, Ballard JD: Toxin inhibition of antimicrobial factors induced by Bacillus anthracis peptidoglycan in human blood. Infect Immun 2013, 81:3693-3702.

45. Artenstein AW, Opal SM: Novel approaches to the treatment of systemic anthrax. Clin Infect Dis 2012, 54:1148-1161.

46. Raymond B, Ravaux L, Memet S, Wu Y, Sturny-Leclere A, Leduc D, Denoyelle C, Goossens PL, Paya M, Raymondjean M, Touqui L: Anthrax lethal toxin down-regulates type-lla secreted phospholipase a(2) expression through MAPK/NF-kappaB inactivation. Biochem Pharmacol 2010, 79:1149-1155.
47. Ali SR, Timmer AM, Bilgrami S, Park EJ, Eckmann L, Nizet V, Karin M: Anthrax toxin induces macrophage death by p38 MAPK inhibition but leads to inflammasome activation via ATP leakage. Immunity 2011, 35:34-44.

48. Kau JH, Sun DS, Huang HS, Lien TS, Huang HH, Lin HC, Chang HH: Sublethal doses of anthrax lethal toxin on the suppression of macrophage phagocytosis. PLoS One 2010, 5:e14289.

49. Maddugoda MP, Stefani C, Gonzalez-Rodriguez D, Saarikangas J, Torrino S, Janel S, Munro P, Doye A, Prodon F, Aurrand-Lions M, Goossens PL, Lafont F, Bassereau P, Lappalainen P, Brochard F, Lemichez E: cAMP signaling by anthrax edema toxin induces transendothelial cell tunnels, which are resealed by MIM via Arp2/3-driven actin polymerization. Cell Host Microbe 2011, 10:464-474.

50. Ebrahimi CM, Sheen TR, Renken CW, Gottlieb RA, Doran KS: Contribution of lethal toxin and edema toxin to the pathogenesis of anthrax meningitis. Infect Immun 2011, 79:2510-2518.

51. Sayner SL, Balczon R, Frank DW, Cooper DM, Stevens T: Filamin A is a phosphorylation target of membrane but not cytosolic adenylyl cyclase activity. Am J Physiol Lung Cell Mol Physiol 2011, 301:L117-124.

52. Sayner SL: Emerging themes of camp regulation of the pulmonary endothelial barrier. Am J Physiol Lung Cell Mol Physiol 2011, 300:L667-678.

53. Nguyen C, Feng C, Zhan M, Cross AS, Goldblum SE: Bacillus anthracisderived edema toxin (ET) counter-regulates movement of neutrophils and macromolecules through the endothelial paracellular pathway. BMC Microbiol 2012, 12:2.

54. Metrich M, Berthouze M, Morel E, Crozatier B, Gomez AM, Lezoualc'h F: Role of the CAMP-binding protein Epac in cardiovascular physiology and pathophysiology. Pflugers Arch 2010, 459:535-546.

55. Morgado M, Cairrao E, Santos-Silva AJ, Verde I: Cyclic nucleotidedependent relaxation pathways in vascular smooth muscle. Cell Mol Life Sci 2012, 69:247-266.

56. Shen Y, Zhukovskaya NL, Zimmer MI, Soelaiman S, Bergson P, Wang CR, Gibbs CS, Tang WJ: Selective inhibition of anthrax edema factor by adefovir, a drug for chronic hepatitis b virus infection. Proc Natl Acad Sci U S A 2004, 101:3242-3247.

57. Laine E, Martinez L, Ladant D, Malliavin T, Blondel A: Molecular motions as a drug target: mechanistic simulations of anthrax toxin edema factor function led to the discovery of novel allosteric inhibitors. Toxins 2012, 4:580-604.

58. Larabee JL, Maldonado-Arocho FJ, Pacheco S, France B, DeGiusti K, Shakir SM, Bradley KA, Ballard JD: Glycogen synthase kinase 3 activation is important for anthrax edema toxin-induced dendritic cell maturation and anthrax toxin receptor 2 expression in macrophages. Infect Immun 2011, 79:3302-3308.

59. Adekoya OA, Sylte I: The thermolysin family (M4) of enzymes: therapeutic and biotechnological potential. Chem Biol Drug Des 2009, 73:7-16.

60. Popov SG, Popova TG, Hopkins S, Weinstein RS, MacAfee R, Fryxell KJ, Chandhoke V, Bailey C, Alibek K: Effective antiprotease-antibiotic treatment of experimental anthrax. BMC Infect Dis 2005, 5:25.

61. Chung MC, Jorgensen SC, Tonry JH, Kashanchi F, Bailey C, Popov S: Secreted Bacillus anthracis proteases target the host fibrinolytic system. FEMS Immunol Med Microbiol 2011, 62:173-181.

62. Chung MC, Jorgensen SC, Popova TG, Tonry JH, Bailey CL, Popov SG: Activation of plasminogen activator inhibitor implicates protease InhA in the acute-phase response to Bacillus anthracis infection. J Med Microbiol 2009, 58:737-744.

63. Chung MC, Popova TG, Jorgensen SC, Dong L, Chandhoke V, Bailey CL, Popov SG: Degradation of circulating von Willebrand factor and its regulator ADAMTS13 implicates secreted Bacillus anthracis metalloproteases in anthrax consumptive coagulopathy. J Biol Chem 2008, 283:9531-9542.

64. Chung MC, Jorgensen SC, Popova TG, Bailey CL, Popov SG: Neutrophil elastase and syndecan shedding contribute to antithrombin depletion in murine anthrax. FEMS Immunol Med Microbiol 2008, 54:309-318.

65. Mukherjee DV, Tonry JH, Kim KS, Ramarao N, Popova TG, Bailey C, Popov S, Chung MC: Bacillus anthracis protease InhA increases blood-brain barrier permeability and contributes to cerebral hemorrhages. PLOS One 2011 6:e17921.

doi:10.1186/1741-7015-11-217

Cite this article as: Remy et al:: $B$. anthracis associated cardiovascular dysfunction and shock: the potential contribution of both non-toxin and toxin components. BMC Medicine 2013 11:217. 